\title{
Self-Perceived Health, Objective Health, and Quality of Life among People Aged 50 and Over: Interrelationship among Health Indicators in Italy, Spain, and Greece
}

\author{
Laura Maniscalco $^{1}(\mathbb{D})$, Silvana Miceli ${ }^{2}$, Filippa Bono ${ }^{3}(\mathbb{D})$ and Domenica Matranga ${ }^{4, *(D)}$ \\ 1 Department of Biomedicine, Neuroscience and Advanced Diagnostics, University of Palermo, \\ Palermo 90127, Italy; laura.maniscalco04@unipa.it \\ 2 Department of Psychology, Educational Science and Human Movement, University of Palermo, \\ Palermo 90128, Italy; silvana.miceli56@unipa.it \\ 3 Department of Economics, Business and Statistics (SEAS), University of Palermo, Palermo 90128, Italy; \\ filippa.bono@unipa.it \\ 4 Department of Health Promotion, Mother and Infant Care, Internal and Specialized Medicine “G. \\ D'Alessandro", University of Palermo, Palermo 90127, Italy \\ * Correspondence: domenica.matranga@unipa.it; Tel.: +39-091-655-3604; Fax: +39-091-591-440
}

Received: 5 February 2020; Accepted: 30 March 2020; Published: 2 April 2020

\begin{abstract}
It is well known that self-perceived health (SPH), even if it is a subjective health indicator, is significantly associated with objective health and quality of life (QoL) in the general population. Whether it can be considered an indicator of cognitive functioning and quality of life in the elderly is still an open issue. This study used a data-driven approach to investigate the interrelationship among SPH, non-communicable diseases (NCDs), QoL, and cognitive functioning to answer this question. The study sample included information about 12,831 people living in Italy, Spain, and Greece, extracted from the Survey on Health, Aging, and Retirement in Europe, in the year 2015. The additive Bayesian networks methodology was used to identify the best directed acyclic graphs (DAG) for SPH, QoL, and NCDs. Results were given as posterior estimates of generalized linear models (GLM) coefficients, with $95 \%$ credibility intervals. Good SPH was associated with a decreasing number of chronic diseases in Italy (coeff $=-0.52,95 \% \mathrm{CI}$ : $[-0.59,-0.44]$ ), Spain (coeff $=-0.53$, 95\%CI: $[-0.60,-0.46])$ and Greece (coeff $=-0.57,95 \% \mathrm{CI}$ : $[-0.64,-0.50])$. Age and Body Mass Index were determinants of NCDs in all countries. QoL of elderly was associated with SPH in Italy $($ coeff $=0.12,95 \%$ CI: $[0.10,0.14])$, Spain $($ coeff $=0.16,95 \% C I$ : $[0.15,0.18])$, and Greece $($ coeff $=0.18$, $95 \%$ CI: $[0.16,0.20])$. The number of NCDs was higher for people who were not employed in Spain (coeff $=0.45,95 \%$ CI: $[0.37,0.53])$ and was decreasing for a unitary increase in years of education in Greece (coeff $=-0.12,95 \% \mathrm{CI}$ : $[-0.14,-0.09])$. As a general rule, the framework of the interrelationship among NCDs, SPH, and QoL was similar for Italy, Spain, and Greece. The connections found among indicators could be proposed to identify strategies for health promotion and healthy aging among people aged 50 and above, which are viable in general and at a country level. Reinforcing strategies targeted at some health indicators could have relevant effects on other related indicators.
\end{abstract}

Keywords: additive Bayesian network; self-perceived health; quality of life; chronic diseases cognitive measures

\section{Introduction}

In the world, the population aged 60 years and over exceeded nine hundred million in 2017, and it is expected to reach nearly 2.1 billion in 2050 [1]. Population aging is a global phenomenon 
and a priority of health policy for all countries since elderly people represent a burden for the active population both in terms of healthcare expenditure and caregiving. Some statistics show that a 65 -year-old individual with a serious chronic illness spends between $\$ 1000$ to $\$ 2000$ more per year in health care services than a similar adult without such a condition [2]. As a consequence, detecting health determinants, identifying actions to postpone the onset of disease, and ensuring healthy aging [3] are strategic issues. Health promotion targeted at elderly people, to keep cognitive functions unaltered and prevent noncommunicable diseases, must be extended to middle-aged people too, as virtuous behaviors and correct lifestyle affecting health in later life must be established earlier in adulthood. Therefore, proposing a comprehensive system of health indicators, which are relevant for elderly and middle-aged people, can be considered a relevant methodologic matter for health policy. This study aimed to identify the interrelationships among health indicators in this specific population. To this end, data were extracted from the Survey on Health, Ageing and Retirement in Europe (SHARE) [4], which is a multidisciplinary and cross-national panel database on health, socio-economic status (SES), social and family networks of people aged 50 or above, living in twenty-seven European countries and Israel [5]. Self-perceived health (SPH), quality of life (QoL) in older ages, chronic or non-communicable diseases (NCDs), global activity limitation, lifestyle, and cognitive functioning are some of the statistical indicators used to capture health multidimensionality of elderly people. It has already been established that SPH supplies information in line with the objective health status [6,7] and quality of life [8] in the general population and that chronic conditions, lifestyle factors, and cognitive functioning are significantly associated with health-related quality of life of adults [9]. Whether SPH can be considered a broad indicator of cognitive functioning and QoL in the elderly is still debated.

SPH measures "subjective health", as it synthesizes all the information regarding an individual's health, such as physical functioning in everyday life, lifestyle conditions, specific disease characteristics (severity and prognosis), and cultural background [10]. The main determinants of SPH are socio-economic factors $[6,11]$ as well as biological, physiological, and psychosocial factors. The World Health Organization (WHO) and the European Commission [12] recommend the use of SPH for health monitoring, and several authors suggest that SPH correlates well with objective health status, in the general population [7], in specific groups [13], and in the older population [14]. SPH is also a comprehensive indicator of lifestyle-related health status because it is significantly associated with some of the lifestyle habits, such as weight change, exercise, smoking, and rest [15].

QoL can be defined according to either a subjective or an objective vision [16]. Following the subjective approach, QoL is based on human needs, emotional wellbeing, and expectations [17]. It is defined as "a conscious cognitive judgment of satisfaction with one's life" [18] or "an individual's perception of their position in life in the context of the culture and value systems in which they live and in relation to their goals, expectations, standards, and concerns" [19]. According to the objective approach [20], QoL is defined as "an overall well-being that comprises objective and subjective evaluations of physical, material, social, and emotional well-being together with the extent of personal development and purposeful activity, all weighted by a personal set of values" [21]. The health status of an individual, with his/her functional abilities and clinical symptoms, together with his/her health perception represents one dimension of QoL [16].

The objective health status of an individual is defined by his/her current or past diseases, both acute and chronic, and clinical parameters [13]. To attain a broad measurement of the objective health for elderly people, NCDs, the lifestyle, global activity limitation, and cognitive functioning should be included as statistical indicators. The global activity limitations indicator is a measure of the functional status of subjects, which corresponds to the occurrence of long-term limitations in usual activities due to a health problem [22]. This indicator is widely recognized as a powerful determinant of SPH in the elderly [23] and represents a key element in the implementation of targeted health interventions. In the same way, the evaluation of cognitive functions represents a very important element in determining the health status of the elderly. In fact, it is through cognitive functions that people perform most of the daily actions, even the simplest ones, such as driving a car or doing the shopping, and maintaining 
social relationships and social activities. There is abundant literature showing that cognitive functions can be enhanced and maintained through protective factors, which are linked to lifestyle [24-26] and quality of life [27].

To make it more intriguing to disentangle factors among health status, health perception, and QoL, the abundant literature showing the individual's socio-economic status as a common determinant must also be considered. It has been shown that lifestyle and socio-economic status (SES) indicators are determinants for SPH [8], QoL in older ages [28], and cognitive functioning [27,29].

On the whole, the first contribution of this study was evaluating the different indicators in an integrated way to show whether SPH can be considered a correlate of cognitive functioning and QoL of people aged 50 and over. The second important contribution of this study was focusing on Italy, Spain, and Greece, which are three Mediterranean European Union (EU) member states that share a similar profile from demographic, health, and care points of view. These three countries enjoy the same fragmented system of welfare provision, with income guarantees linked to work position, a high percentage of social expenditure financed through contributions, and a strong reliance on family and on the charitable sector [30]. In Italy, Spain, and Greece, welfare has also undergone major transformations over the past few years. In fact, between 2009 and 2010, Greece experienced a serious financial crisis with the highest deficit rate in the EU, which led to a tightening of fiscal policy, mainly centered on cuts to welfare spending. In the years immediately following, Italy and Spain also underwent important austerity policies that inevitably produced significant effects on the retirement system, on labor market policies, but above all on health policies. This has created significant problems for the maintenance of social protection systems in Southern Europe. There is, therefore, an evident need to monitor the trend of indicators highlighted in our study (NCDs, SPH, and QoL) in the three different geographical contexts, to implement targeted interventions in the field of public health research and practice.

\section{Data and Methods}

Data for this study was extracted from the sixth (year $=2015$ ) wave of the SHARE Survey.

Data collection was executed through computer-assisted personal interviews, which were conducted face-to-face with the target respondent and willing partners or spouses. For people affected by cognitive limitations, including Alzheimer's disease, dementia, and senility, information was obtained through a proxy interview. Some interviews were supplemented with the participant's completion of a written questionnaire, which included additional questions on subjects such as mental and physical health, health care, and social networks.

For the purposes of the current investigation, only the information concerning people from Spain, Italy, and Greece, was extracted. Only normal aging was considered, so people with Alzheimer's disease, dementia, and senility were excluded. Therefore, the study sample consisted of 12,831 people, of which 4110 were Italian (32\%), 4308 were Spanish (34\%), and 4413 were Greek (34\%). Data are

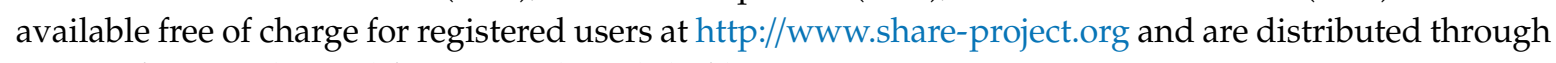
twenty-five regular and four special module files.

\subsection{Variables}

To measure SPH, the single-item question "In general, would you say your health is ... " was asked, with ordered response categories on a five-point scale from excellent to poor.

QoL in older ages was measured through the 12-item version of the CASP scale (CASP-12), which is the reduced version of the 19-item CASP scale and measures the four dimensions of needs Control, Autonomy, Self-realization, and Pleasure. The questions involved a list of statements used to describe people's lives or how people feel and what people think, with answers coded on a 4-point scale indicating how often (1. Often, 2. Sometimes, 3. Rarely, and 4. Never), if at all, the interviewed person had experienced these feelings and thoughts. All items were recorded in such a way that higher scores indicate a higher level of QoL. CASP-12 ranged between 12 and 48 [31,32]. 
The number of NCDs and the global activity limitation index were included as measures of objective health status. The global activity limitation index corresponded to the question: "For at least the past 6 months, to what extent have you been limited because of a health problem in activities people usually do? Would you say you have been ..." severely limited/limited but not severely or/not limited at all? For the purposes of the study, answers were categorized as "not limited" vs. "limited". Cognitive functioning was assessed through two memory tests and one executive function. For the memory tests, we used the immediate (ITest) and delayed (DTest) verbal recall test from the Ten-Word Delayed Recall Test, both ranging between 0 and 10 [26]. To examine executive function, we used the score of a semantic verbal fluency (FTest) test consisting of asking the participant to name as many animals as possible correctly during a one-minute period. This score ranged between 0 and 100. In this type of task, in addition to the linguistic component, there is "fluency" that is based on non-linguistic skills, such as selective attention and rapidity, which are necessary to guide the search and recovery of elements in the semantic memory [33]. The correct execution of the test assumes the integrity of the working memory, too [34]. Gender, age, living in a couple, and country of residence were included as demographic variables, while years of education, current job status, household total net income, and household net worth were chosen as SES variables. To measure lifestyle, we included Body Mass Index (BMI), smoking status ("Yes" vs. "No"), and physical inactivity ("Yes" vs. "No"). Limited to multivariable statistical analysis, some variables were transformed into binary ones: age ("> $>65^{\prime \prime}$ vs. " $<=65$ "), current job status ("Not employed", which included homemakers/permanently sick/retired/unemployed vs. "Employed", which included employed/self-employed/other), living in a couple ("Not in couple" vs. "In couple").

\subsection{Statistical Methods}

Continuous variables were described by the following summary statistics: mean and standard deviation (the latter is reported in brackets), median, and range. Categorical variables were analyzed as counts and percentages. To assess the statistical significance of the difference among countries, the Chi-squared test was used for categorical variables, and the ANOVA test was used for continuous variables.

The interrelationships among SPH, the objective health status, QoL, cognitive tasks, and SES were modeled through additive Bayesian networks (ABNs), a class of probabilistic models that unify Bayesian networks and generalized linear models (GLM) [35]. A Bayesian network (BN) uses an acyclic directed graph (DAG) to represent a set of random variables as nodes and their conditional dependencies as arrows between the nodes. A node is called an ancestor if it influences another variable, which, in turn, assumes the role of the descendant. The DAG is called acyclic because a node could not be its own ancestor or its own descendent. A BN usually models the joint distribution of a set of random variables through a multivariate continuous or discrete distribution. These assumptions can be too restrictive for real data analysis and more flexible graphical models are necessary for mixed (continuous and discrete) random variables. Recently, Pittavino et al. [36] proposed ABNs as an extension of BNs by allowing each random variable to be modeled as an exponential distribution through a generalized linear model [30]. The ABN considers all the variables jointly and aims to identify all direct and indirect relationships between them. An edge between two variables in the ABN model represents a "direct" relationship, whereas an "indirect" relationship is defined as a relationship between two variables through an intermediate variable. As the $\mathrm{ABN}$ is defined in a Bayesian context, each parameter, and the DAG as a whole, are defined as random variables. In this paper, binary variables were modeled through a binomial distribution and logit link, quantitative variables through a normal distribution with identity link, while count variables were modeled through a Poisson distribution with a log link. A uniform prior was given to the DAG structure, uninformative Gaussian priors were applied for the parameters at each node, and diffuse Gamma distributions with shape and scale of 0.001 were used for the precision. 
To identify the best DAG, an exact search method was used with the log marginal likelihood as the goodness of fit metric [35]. An exact search is based on the increase in the maximum number of parents allowed per node (the number of covariates allowed in each model) until the goodness of fit remains constant. This iterative approach is usually applied to avoid the increase in computational time needed to search across the model space of DAGs with larger parent limits. In this paper, the model selection procedure considered from one to twelve possible parents per node. In the second step, the marginal posterior log odds ratio and its $95 \%$ credibility interval was estimated for each parameter from the posterior distribution, expressed by the optimal DAG identified at the first step. In line with other literature, the log marginal likelihood was not checked for overfitting because the study sample was of a large size [37]. Results of ABN analysis were expressed as posterior estimates of GLM coefficients, with $95 \%$ credibility intervals.

Data were analyzed using the $R$ software (version 3.3.2), and the ABN methodology was implemented using the "abn" package [38] in the R environment. The "fitabn" function was used to estimate the parameters of the linked variables and to represent their relationships graphically. For the sake of clarity, the graphics resulting from the "abn" package were adapted to show the parents of each health outcome one by one. A $p$-value $<0.05$ was considered statistically significant. In this study, the estimated ABNs reported banned edges directed towards gender and age, since it is not theoretically possible for these variables to be influenced by other covariates.

\section{Results}

\subsection{Sample Description}

The sample included 5695 males (44\%) and 7136 females (56\%). The distribution by gender was similar in the three countries, while age was on average significantly higher in Spain (68.3 (9.9)) compared to Greece $(66.9(10.0))$ and Italy $(65.7(9.4))(p<0.001)$. The years of education were $8.8(4.6)$, on average, with Greek people being significantly more educated than Spaniards and Italians. On average, people within the sample were overweight (the average BMI was 27.0 (4.2)), mostly physically inactive ( $84 \%$ of the sample), and living in a couple $(75 \%)$. The highest percentage of current smokers was observed in Greece ( $47 \%$ ), followed by Italy $(39 \%)$, and then Spain $(36 \%)$. Nearly half of the sample was retired (47\%), with the highest percentage of retired people in Italy $(49 \%)$ compared to Spain and Greece (both $46 \%$ ).

With regards to health indicators, people were, in general, affected by more than one NCD (1.7 (1.5)) with a slight difference between Greece and Spain and a bit more difference in Italy (1.5 (1.5)). Of the three examined cognitive tasks, there was a lower value for the executive task for the Greeks (12.4 (5.1)) compared to the Italians and Spaniards; there was a lower value for both memory tasks for Spanish subjects (4.2 (1.8) for the ITest and 2.8 (1.9) for DTest) compared to the other two groups. Regarding QoL in older ages, the CASP-12 score was higher for Spanish subjects (35.5 (6.2)) compared to the Italians and Greeks. Thirty-seven percent of the whole sample perceived poor or fair health, varying from a minimum of $31 \%$ observed for Greeks to $38 \%$ and $40 \%$ of Italians and Spaniards, respectively. Thirty-four percent of the whole sample suffered from global activity limitations, with a minimum of $28 \%$ for Greece to $36 \%$ for Spain and $38 \%$ for Italy (Table 1 ). The correlation matrix between pairs of variables is given as Supplement materials.

Table 1. Descriptive statistics ${ }^{\S}$ of 12,931 people aged 50 years and more living in Italy, Spain, and Greece.

\begin{tabular}{|c|c|c|c|c|c|}
\hline & Greece & Italy & Spain & Total Sample & $p$ \\
\hline \multicolumn{6}{|l|}{ Age ** } \\
\hline Range & $(50-95)$ & $(50-102)$ & $(50-102)$ & $(50-102)$ & $<0.0001$ \\
\hline Median & 66 & 65 & 67 & 66 & \\
\hline Mean(SD) & $66.86(9.96)$ & $65.72(9.41)$ & $68.25(10.06)$ & $66.96(9.87)$ & \\
\hline
\end{tabular}


Table 1. Cont.

\begin{tabular}{|c|c|c|c|c|c|}
\hline & Greece & Italy & Spain & Total Sample & $p$ \\
\hline \multicolumn{6}{|l|}{ Years of education ** } \\
\hline Range & $(0-25)$ & $(0-25)$ & $(0-25)$ & $(0-25)$ & $<0.0001$ \\
\hline Median & 9 & 8 & 8 & 8 & \\
\hline Mean(SD) & $9.51(4.37)$ & $8.59(4.31)$ & $8.33(4.95)$ & $8.82(4.58)$ & \\
\hline \multicolumn{6}{|l|}{ Household net income ** } \\
\hline Range & $(0-47,170)$ & $(0-47,040)$ & $(0-47,000)$ & $(0-47,170)$ & $<0.0001$ \\
\hline Median & 10310 & 17580 & 14010 & 13620 & \\
\hline Mean(SD) & $11,860(9163.47)$ & $\begin{array}{c}18,560 \\
(11,291.43)\end{array}$ & $\begin{array}{c}15,540 \\
(10,022.52)\end{array}$ & $\begin{array}{c}15,250 \\
(10,531.93)\end{array}$ & \\
\hline \multicolumn{6}{|l|}{ Household net worth ${ }^{* *}$} \\
\hline Range & $\begin{array}{c}(-169,200 \\
520,700)\end{array}$ & $\begin{array}{l}(-48,000 \\
541,700)\end{array}$ & $\begin{array}{l}(-94,350 \\
543,300)\end{array}$ & $\begin{array}{c}(-169,200 \\
543,300)\end{array}$ & $<0.0001$ \\
\hline Median & 80,000 & 160,000 & 153,900 & 128,000 & \\
\hline Mean(SD) & $\begin{array}{c}105,000 \\
(100,907.5)\end{array}$ & $\begin{array}{c}178,600 \\
(134,075.1)\end{array}$ & $\begin{array}{c}174,300 \\
(123,691.3)\end{array}$ & $\begin{array}{c}151,800 \\
(124,695.9)\end{array}$ & \\
\hline \multicolumn{6}{|l|}{$\mathrm{BMI}^{+* *}$} \\
\hline Range & (15.12 57.37) & (15.79 50.71) & (15.06 56.80) & (15.06 57.37) & $<0.0001$ \\
\hline Median & 26.83 & 25.88 & 26.64 & 26.45 & \\
\hline Mean(SD) & $27.36(4.23)$ & $26.35(4.13)$ & $27.10(4.27)$ & $26.95(4.23)$ & \\
\hline Gender* & & & & & N.S. \\
\hline Female & $2484(56 \%)$ & $2260(55 \%)$ & $2392(56 \%)$ & $7136(56 \%)$ & \\
\hline Male & $1929(44 \%)$ & $1850(45 \%)$ & $1916(44 \%)$ & $5695(44 \%)$ & \\
\hline Living in couple * & & & & & $<0.0001$ \\
\hline In couple & $3311(75 \%)$ & $3230(79 \%)$ & $3402(79 \%)$ & $9943(78 \%)$ & \\
\hline Not in couple & $1102(25 \%)$ & $880(21 \%)$ & $906(21 \%)$ & $2888(22 \%)$ & \\
\hline Current job status* & & & & & $<0.0001$ \\
\hline Employed & $1060(24 \%)$ & $1005(24 \%)$ & $961(22 \%)$ & $3026(24 \%)$ & \\
\hline Not employed & $3353(76 \%)$ & $3105(76 \%)$ & $3347(78 \%)$ & $9805(76 \%)$ & \\
\hline Current smoking status* & & & & & 0.047 \\
\hline No & $2324(53 \%)$ & $2493(61 \%)$ & $2766(64 \%)$ & $7583(59 \%)$ & \\
\hline Yes & $2089(47 \%)$ & $1617(39 \%)$ & $1542(36 \%)$ & $5248(41 \%)$ & \\
\hline Physical inactivity * & & & & & $<0.0001$ \\
\hline No & 4079 (92\%) & $3129(76 \%)$ & $3606(84 \%)$ & $10814(84 \%)$ & \\
\hline Yes & $334(8 \%)$ & $981(24 \%)$ & $702(16 \%)$ & $2017(16 \%)$ & \\
\hline NCDs ** & & & & & $<0.0001$ \\
\hline Range & $(0-12)$ & $(0-9)$ & $(0-9)$ & $(0-12)$ & \\
\hline Median & 1 & 1 & 2 & 1 & \\
\hline Mean(SD) & $1.70(1.57)$ & $1.49(1.45)$ & $1.77(1.49)$ & $1.66(1.51)$ & \\
\hline \multicolumn{6}{|l|}{ Fluency ** } \\
\hline Range & $(0-77)$ & $(0-70)$ & $(0-93)$ & $(0-93)$ & $<0.0001$ \\
\hline Median & 12 & 15 & 15 & 14 & \\
\hline Mean(SD) & $12.44(5.09)$ & $15.67(6.66)$ & $15.61(6.68)$ & $14.54(6.35)$ & \\
\hline \multicolumn{6}{|l|}{ ITest $^{+* *}$} \\
\hline Range & $(0-10)$ & $(0-10)$ & $(0-10)$ & $(0-10)$ & $<0.0001$ \\
\hline Median & 5 & 5 & 4 & 5 & \\
\hline Mean(SD) & $5.04(1.65)$ & $4.81(1.73)$ & $4.22(1.76)$ & $4.69(1.75)$ & \\
\hline \multicolumn{6}{|l|}{ DTest $^{+* *}$} \\
\hline Range & $(0-10)$ & $(0-10)$ & $(0-10)$ & $(0-10)$ & $<0.0001$ \\
\hline Median & 3 & 3 & 3 & 3 & \\
\hline Mean(SD) & $3.46(1.86)$ & $3.32(1.91)$ & $2.75(1.89)$ & $3.17(1.91)$ & \\
\hline \multicolumn{6}{|l|}{$\mathrm{QoL}^{+* *}$} \\
\hline Range & $(15-48)$ & $(12-48)$ & $(12-48)$ & $(12-48)$ & $<0.0001$ \\
\hline Median & 32 & 34 & 37 & 34 & \\
\hline Mean(SD) & $31.69(5.58)$ & $34.13(6.23)$ & $35.95(6.26)$ & $33.9(6.28)$ & \\
\hline Global activity limitation * & & & & & $<0.0001$ \\
\hline Limited & $1257(28 \%)$ & $1567(38 \%)$ & $1535(36 \%)$ & $4359(34 \%)$ & \\
\hline Not limited & $3156(72 \%)$ & $2543(62 \%)$ & $2773(64 \%)$ & $8472(66 \%)$ & \\
\hline $\mathrm{SPH}^{*}$ & & & & & $<0.0001$ \\
\hline Poor & $295(7 \%)$ & $334(8 \%)$ & $462(11 \%)$ & $1091(9 \%)$ & \\
\hline Fair & $1043(24 \%)$ & $1248(30 \%)$ & $1261(29 \%)$ & $3552(28 \%)$ & \\
\hline Good & $1568(36 \%)$ & $1570(38 \%)$ & $1766(41 \%)$ & $4904(38 \%)$ & \\
\hline Very good & $1212(27 \%)$ & $669(16 \%)$ & $671(16 \%)$ & $2552(20 \%)$ & \\
\hline Excellent & $295(7 \%)$ & $289(7 \%)$ & $148(3 \%)$ & $732(6 \%)$ & \\
\hline
\end{tabular}

${ }^{+}$BMI=Body Mass Index, NCDs=Non-communicable diseases, ITest=Immediate verbal recall test, DTest=Delayed verbal recall test, $\mathrm{QoL}=\mathrm{Quality}$ of Life, $\mathrm{SPH}=$ Self-perceived health. ${ }^{\S}$ Results in rows are range, median, and mean (SD) for quantitative indicators and counts (\%) for qualitative indicators. NS means not statistically significant.

* The Chi-squared test was used for categorical variables, ${ }^{* *}$ the ANOVA test for continuous variables. 


\subsection{Description of DAGs for Spain, Greece, and Italy}

To find the best DAG, the maximum number of parents allowed for each node has to increase until the log marginal likelihood remains constant. The model selection procedure identified a maximum number of parents equal to six for all countries.

The final globally optimal DAGs, including all variables and one edge for every association, both direct and indirect, are shown, respectively, for Italian, Greek, and Spanish people (Figures 1a, 2a and 3a). For the sake of clarity, a graph of the different interrelationships with one health outcome at a time (NCDs, $\mathrm{SPH}, \mathrm{QoL}$ ) is presented for each country. Posterior estimates of GLM coefficients and respective 95\% credibility intervals are shown in Table 2.

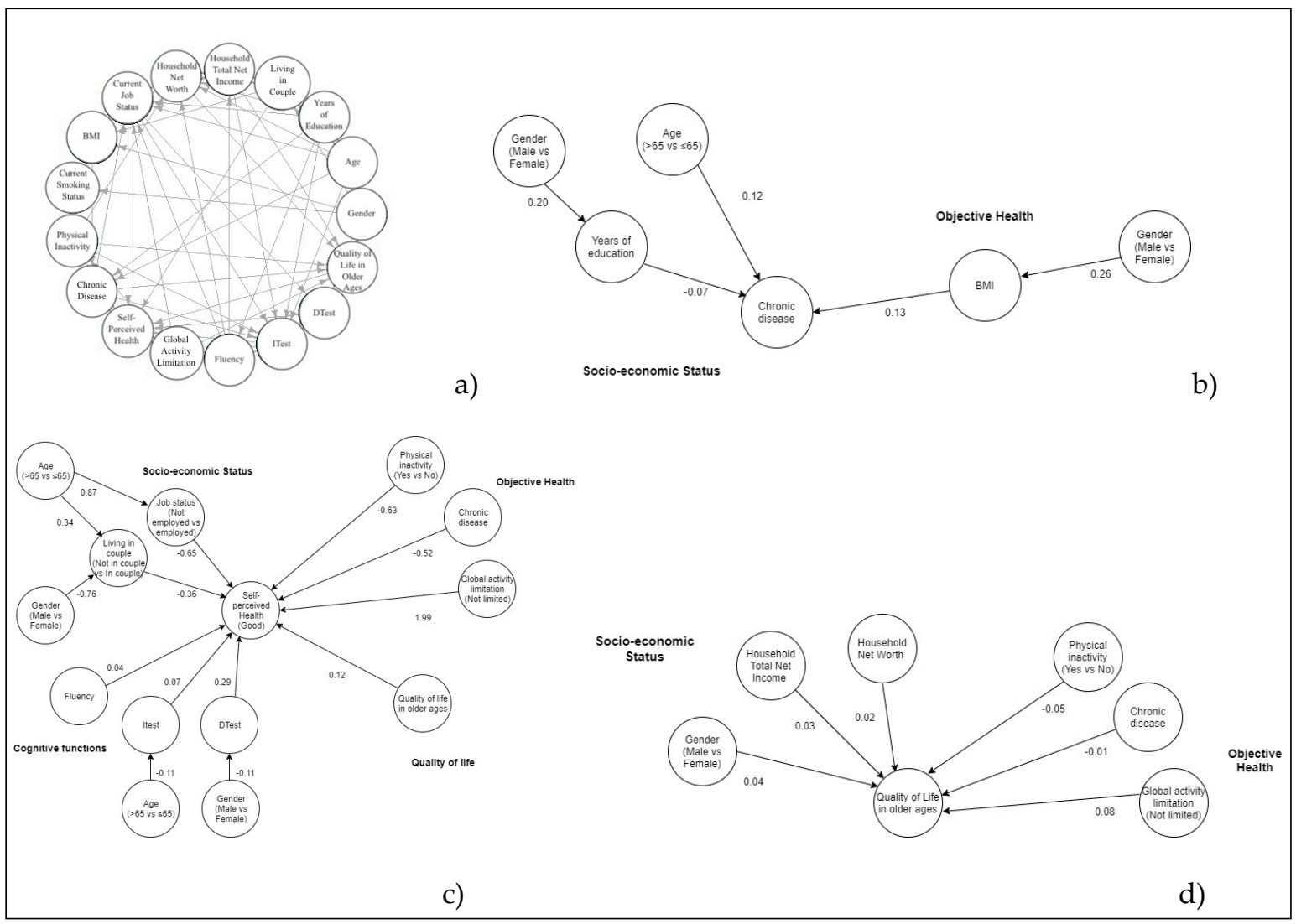

Figure 1. Additive Bayesian networks describing the interrelationship for all health indicators (a), chronic diseases (b), Self-perceived health (c), quality of life (QoL) (d) for Italian elderly. Source: The Survey on Health, Aging, and Retirement in Europe, wave 6th, 2015 year. BMI = Body Mass Index, Itest $=$ Immediate verbal recall test, Dtest $=$ Delayed verbal recall test.

Relating the number of NCDs (Figures $1 b, 2 b$ and $3 b$ ), the optimal DAGs for Italian, Greek, and Spanish people show a direct association with BMI and age. For Spanish subjects, the number of NCDs is significantly higher for people not in employment. In Greek and Italian DAGs, the association with gender looks to be mediated by years of education and living in a couple (Greece only).

Relating to SPH (Figures 1c, 2c and 3c), the three DAGs show better-perceived health by decreasing the number of NCDs and by increasing the DTest. People without global activity limitations are more likely to enjoy better health, while those who are not in employment or are physically inactive are prone to worse health perception. Moreover, the Italian and Greek DAGs show people not living in a couple perceiving worse health than those living in a couple. SPH shows a direct association with QoL in the Italian and Spanish DAG. Males perceive better health than females in the Spanish DAG. The association with age seems to be mediated by current job status and ITest in all DAGs. Regarding 
gender, the indirect association with SPH passes through the ITest for Spanish DAGs and through the DTest and living in a couple for Greek and Italian DAGs.

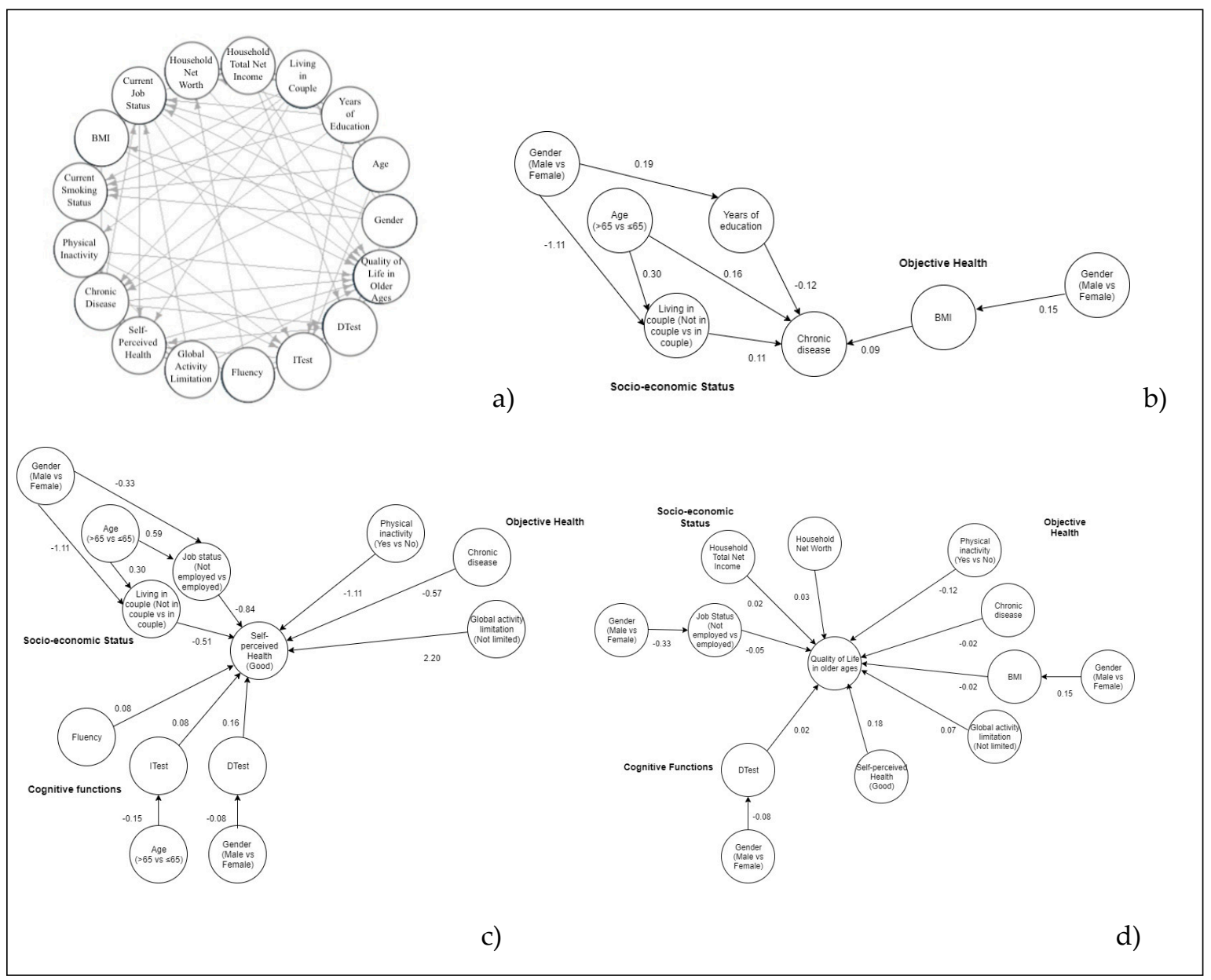

Figure 2. Additive Bayesian networks describing the interrelationship for all health indicators (a), chronic diseases (b), Self-perceived health (c), QoL (d) for Greek elderly. Source: The Survey on Health, Aging, and Retirement in Europe, wave 6th, 2015 year. BMI = Body Mass Index, Itest = Immediate verbal recall test, Dtest $=$ Delayed verbal recall test.

In the Italian, Greek, and Spanish samples, QoL of elderly (Figures $1 \mathrm{~d}, 2 \mathrm{~d}$ and $3 \mathrm{~d}$ ) is better for people without global activity limitations and for people with higher household total net income and household net worth. QoL worsens for physically inactive people and by increasing the number of NCDs. Finally, in the Greek DAG, QoL shows a direct association with health perception. 


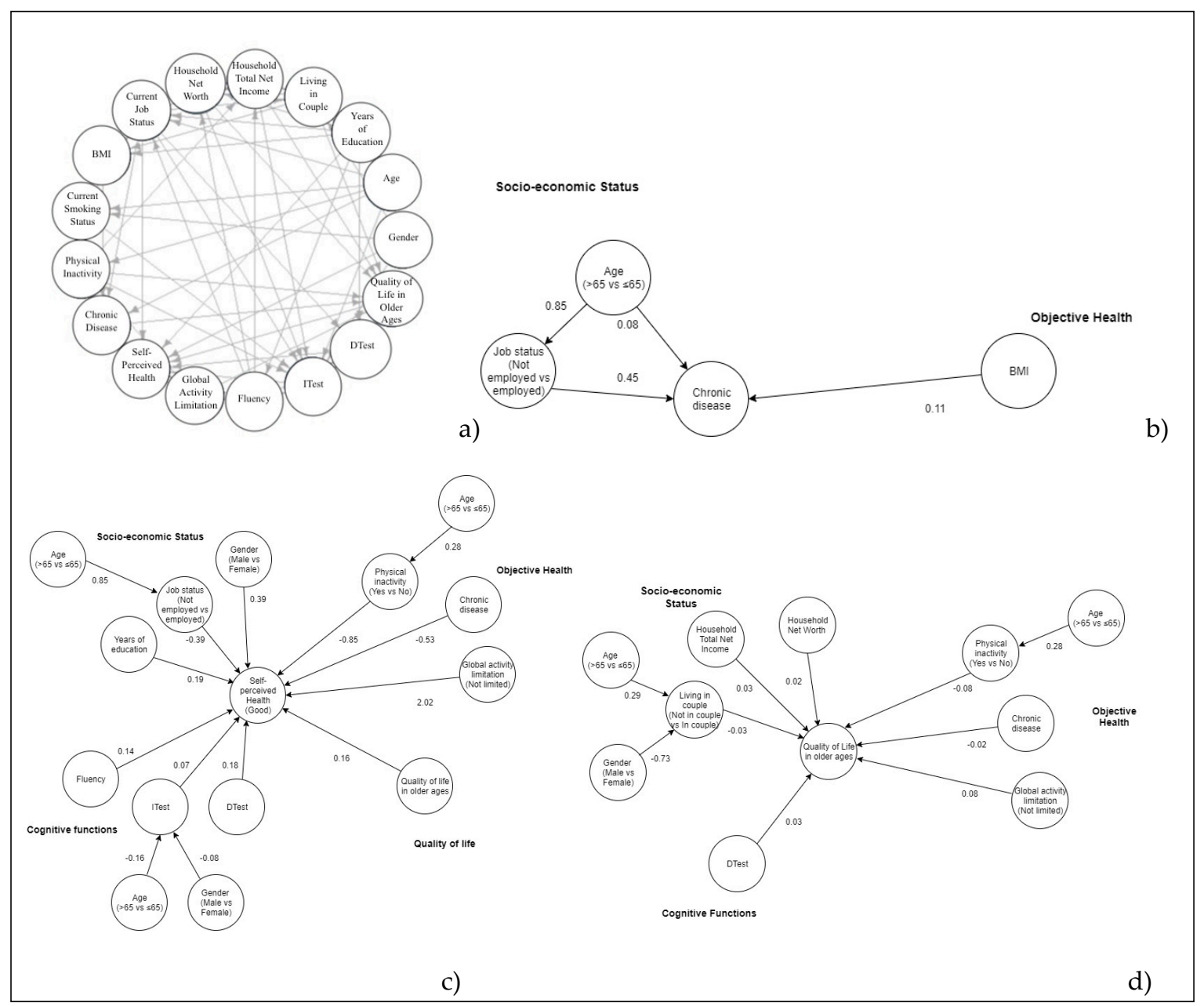

Figure 3. Additive Bayesian networks describing the interrelationship for all health indicators (a), chronic diseases (b), Self-perceived health (c), QoL (d) for Spanish elderly. Source: The Survey on Health, Aging, and Retirement in Europe, wave 6th, 2015 year. BMI = Body Mass Index, Itest = Immediate verbal recall test, Dtest $=$ Delayed verbal recall test.

Table 2. Posterior generalized linear models (GLM) estimates of direct effects, with $95 \%$ credibility intervals, resulting from additive Bayesian networks (ABN) models in Italy, Spain, and Greece, 2015 year.

\begin{tabular}{cccc}
\hline \multirow{2}{*}{ NCDs $^{\dagger}$} & Italy & Greece $^{\S}$ & Spain $^{\S}$ \\
\cline { 2 - 4 } & $\beta[95 \% \mathrm{CI}]$ & $\beta[95 \% \mathrm{CI}]$ & $\beta[95 \% \mathrm{CI}]$ \\
\hline BMI $^{\dagger}$ & $0.13[0.11,0.16]$ & $0.09[0.07,0.12]$ & $0.11[0.08,0.13]$ \\
\hline Years of education & $-0.07[-0.09,-0.05]$ & $-0.12[-0.14,-0.09]$ & \\
\hline Age ( $\geq 65$ vs. $<65)$ & $0.12[0.09,0.14]$ & $0.16[0.14,0.17]$ & $0.08[0.06,0.10]$ \\
\hline $\begin{array}{c}\text { Living in couple (Not in couple vs. } \\
\text { in couple) }\end{array}$ & $0.11[0.04,0.17]$ & \\
\hline $\begin{array}{c}\text { Current job status (not employed } \\
\text { vs. employed) }\end{array}$ & & $0.45[0.37,0.53]$ \\
\hline
\end{tabular}


Table 2. Cont.

\begin{tabular}{|c|c|c|c|}
\hline & Italy & Greece & Spain \\
\hline $\mathrm{SPH}^{\dagger}$ & $\beta[95 \% \mathrm{CI}]$ & $\beta[95 \% \mathrm{CI}]$ & $\beta[95 \% \mathrm{CI}]$ \\
\hline $\mathrm{NCDs}^{\dagger}$ & $-0.52[-0.59,-0.44]$ & $-0.57[-0.64,-0.50]$ & $-0.53[-0.60,-0.46]$ \\
\hline ITest $^{\dagger}$ & $0.07[0.04,0.11]$ & $0.08[0.04,0.12]$ & $0.07[0.03,0.10]$ \\
\hline Dtest $^{\dagger}$ & $0.29[0.26,0.34]$ & $0.16[0.11,0.21]$ & $0.18[0.14,0.23]$ \\
\hline Fluency & $0.04[0.02,0.06]$ & $0.08[0.06,0.11]$ & $0.14[0.12,0.16]$ \\
\hline $\begin{array}{l}\text { Global activity limitations (Not } \\
\text { limited vs. Limited) }\end{array}$ & $1.99[1.83,2.16]$ & $2.20[2.03,2.40]$ & $2.02[1.86,2.21]$ \\
\hline $\mathrm{QoL}^{+}$ & $0.12[0.10,0.14]$ & & $0.16[0.15,0.18]$ \\
\hline $\begin{array}{l}\text { Living in couple (Not in couple vs. } \\
\text { in couple) }\end{array}$ & $-0.36[-0.53,-0.20]$ & $-0.50[-0.71,-0.30]$ & \\
\hline $\begin{array}{c}\text { Current job status (not employed } \\
\text { vs. employed) }\end{array}$ & $-0.65[-0.83,-0.47]$ & $-0.84[-1.08,-0.64]$ & $-0.39[-0.61,-0.18]$ \\
\hline Physical inactivity (Yes vs. No) & $-0.63[-0.81,-0.46]$ & $-1.11[-1.43,-0.85]$ & $-0.85[-1.06,-0.65]$ \\
\hline Gender (Male vs. Female) & & & $0.39[0.23,0.54]$ \\
\hline Years of education & & & $0.19[0.12,0.25]$ \\
\hline QoL $^{+}$ & $\begin{array}{c}\text { Italy } \\
\beta[95 \% \mathrm{CI}]\end{array}$ & $\begin{array}{c}\text { Greece } \\
\beta[95 \% \mathrm{CI}]\end{array}$ & $\begin{array}{c}\text { Spain } \\
{[95 \% \mathrm{CI}]}\end{array}$ \\
\hline $\begin{array}{c}\text { Global activity limitations (Not } \\
\text { limited vs. Limited) }\end{array}$ & $0.08[0.06,0.09]$ & $0.07[0.05,0.09]$ & $0.08[0.06,0.09]$ \\
\hline Household Total net income & $0.03[0.02,0.04]$ & $0.02[0.01,0.03]$ & $0.02[0.02,0.04]$ \\
\hline Household net worth coeff & $0.02[0.01,0.03]$ & $0.03[0.02,0.04]$ & $0.03[0.01,0.03]$ \\
\hline Gender (Male vs. Female) & $0.04[0.03,0.05]$ & & \\
\hline Physical inactivity (Yes vs. No) & $-0.05[-0.06,-0.03]$ & $-0.12[-0.15,-0.09]$ & $-0.08[-0.09,-0.06]$ \\
\hline $\mathrm{SPH}^{\dagger}$ (Good vs. Less than good) & & $0.18[0.16,0.20]$ & \\
\hline $\mathrm{BMI}^{+}$ & & $-0.02[-0.02,-0.01]$ & \\
\hline $\mathrm{NCDs}^{\dagger}$ & & $-0.02[-0.02,-0.01]$ & $-0.02[-0.02,-0.01]$ \\
\hline ITest $^{\dagger}$ & & $0.02[0.01,0.02]$ & $0.03[0.02,0.03]$ \\
\hline $\begin{array}{c}\text { Current job status (not employed } \\
\text { vs. employed) }\end{array}$ & & $-0.05[-0.07,-0.03]$ & \\
\hline $\begin{array}{l}\text { Living in couple (Not in couple vs. } \\
\text { in couple) }\end{array}$ & & & $-0.03[-0.04,-0.01]$ \\
\hline
\end{tabular}

${ }^{\dagger}$ NCDs = Non-communicable diseases, SPH = Self-perceived health, BMI = Body Mass Index, ITest = Immediate verbal recall test, DTest $=$ Delayed verbal recall test, $\mathrm{QoL}=$ Quality of Life. A cell is empty when there is not an edge in the corresponding directed acyclic graphs (DAG).

\section{Discussion}

Through the discovery of interrelationship among SPH, objective health, and QoL, this study could demonstrate that SPH is significantly associated with cognitive functioning and QoL of people aged 50 and above, besides also confirming the well-known association with chronic diseases. In this way, knowledge can be pursued regarding what is actionable for health promotion and wellbeing improvement of elderly people in these Mediterranean countries. Maintaining and increasing functional capacity, maintaining or improving self-care, and fostering one's social network, and also social participation and integration [27], contribute to a longer, more independent, and self-sufficient quality of life [39] with an important impact on individual health status. At the policy level, infrastructure investments can be suggested to favor active aging of elderly people, such as recreation centers with a supply of cultural programs, physical training, and other activities which stimulate high cognitive involvement to enhance executive functions. 
These three Mediterranean countries were among those with the most pronounced pace of demographic change between 1974 and 2014. In 2015, these countries reported the highest peak in the proportion of elderly people in the population (between 18\% and $21 \%$ ), and fewer than $20 \%$ were living alone. They recorded the largest gender gaps in favor of men regarding the number of healthy life years at the age of 65 . In addition, by combining the information on healthy life years with life expectancy, the biggest differences between males and females were found again in Spain and Greece, apart from Portugal and Cyprus [40].

As a general rule, the framework of this interrelationship was consistent in all three countries. The components of objective health and cognitive functions came out as determinants of SPH. In particular, the role of delayed recall was more remarkable compared to immediate recall and semantic verbal fluency, as it is the most sensitive among the measurements of cognitive impairment [41]. With regards to the components of objective health, many other studies showed a significant increase in the prevalence of all chronic diseases in association to lower health perception [6,7] and demonstrated that global activity limitation relates to SPH and mental and physical health problems [42].

In the current literature, the labor market, the educational system, and socio-demographic characteristics have been found as determinants of SPH in older age [8,43]. In addition, in our study, job status was found as a determinant of SPH in all three countries, but there was a significant association with years of education and gender only in Spain, with the major likelihood of perceiving good health for males compared to females [44]. Analogously, our finding confirms that a higher level of education is associated with better health perception among Spanish people aged 50 and above [45].

Regarding NCDs, age and BMI were found as determinants in all three countries. This result is in line with the causal trajectory of risk factors of NCDs, with four levels of causation from far away to closer to the disease, these being: physiological factors, lifestyle influences, environmental influences, and social structure. Age and BMI belong to the first and the fourth level, respectively [46]. Current job status was found to be associated with the number of NCDs in Spain, in agreement with other literature [47] Moreover, education is confirmed as a determinant both in Italy and Greece [48,49]. Not living in a couple was another risk factor for NCDs among elderly Greeks. It can be explained as lonely people are more prone to engage in unhealthier behaviors (smoking, low interest in health screening), to experience more psychological distress, and not have time to take care of themselves with physical activity [49].

For both SPH and NCDs, income did not play any role. This result is in line with other literature using the SHARE dataset, as it was found that both the number of NCDs and socioeconomic inequality in NCDs were more likely to be related to differences in education than income [50].

Another finding of the study was that people without any global activity limitation enjoyed better QoL in all three samples. QoL and health status are different concepts, as the first one is more associated with mental health, the second one more to physical functioning [51]. However, the current study showed that these constructs are correlated.

The relation between SPH and QoL can be twofold. In some cases, self-perceived health showed a direct relationship with quality of life. The way an elderly person perceives his/her own health condition steers his/her lifestyle and inevitably influences quality of life. In other cases, quality of life goes beyond the perceived state of health: for example, having good social relationships, being active and able to participate in socially significant activities can be very important for older people. In the three countries, our study showed a direct association between QoL and health perception. This result is in line with several other studies where QoL was associated with health improvement and the promotion of active aging [28]. Other studies have considered SPH as a direct measure of QoL, without considering other concepts, such as health or psychological wellbeing [52,53].

The study showed that the association with age for all health outcomes was not only direct but seemed to be mediated by cognitive measurements. This result, that should be confirmed with appropriate statistical methods, has important implications for the development of support practices related to the maintenance and enhancement of cognitive functions, considered as factors of protection 
from psychosocial risk. In fact, today, we tend to worry about our mental functioning when the decline is already evident, and we rarely take a preventive and empowering approach. Therefore, it becomes a priority to identify effective cognitive enhancement strategies that, by operating on the mechanisms of brain plasticity and contributing to the maintenance of a good cognitive reserve, are able to mediate the effects of aging.

The proposed methodology allowed us to study the associations among several variables simultaneously and to grasp the natural complexity of data more effectively than GLM. While GLM addresses the direct dependencies between risk factors and one single outcome, the ABN models the dependencies (both direct and indirect) among all the variables jointly. Compared to other statistical methods, the $\mathrm{ABN}$ focused on structure discovery with the aim of representing the core data generation process.

The main strength of our study was using a data-driven approach to infer the relationship among several health indicators and their determinants. Different studies have investigated the relationship among socioeconomic and lifestyle determinants with health outcomes one by one [31,54]. Few considered the relationship between pairs of health outcomes, such as SPH and objective health status [7], SPH and NCDs [6], NCDs and QoL [55], and SPH and QoL [8]. A recent study took into account NCDs, cognitive functioning, and lifestyle factors, but did not include SPH and global activity limitations [9].

There are, however, some limits to the present study. The first one regards some aspects of the variables used in this analysis. In fact, we could have obtained other results if we had used other QoL indicators, or different cognitive tasks from the three used in this paper. However, these tasks measure specific aspects of cognition, which deteriorate more with age, showing a constant decline both in healthy subjects and in subjects affected by Alzheimer's disease [56]. Another limitation concerns the study design. As it is a cross-sectional study, it does not allow for testing of cause-effect relationships, but it helps us to formulate research hypotheses that could be the basis of subsequent confirmatory studies. Finally, another limitation regards the occurrence of selection bias, since the study subjects were the survivors of their cohorts following exclusion of people with cognitive impairments, and thus by definition the healthiest.

The connections found among different health dimensions could be relevant to identify intervention strategies that are viable in general and at a country level. It was demonstrated that acting to combat cognitive decline, to reduce the effects of global activity limitations in daily life, and to support a correct lifestyle to prevent the occurrence of NCDs should improve all health outcomes for middle-aged and elderly people. Furthermore, in line with the Health 2020 Agenda [57], the analysis of health indicators provides useful information for the design and implementation of health promotion strategies and health inequality reduction that take into account the specific characteristics of each country.

Supplementary Materials: The following are available online at http://www.mdpi.com/1660-4601/17/7/2414/s1, Table S1: Correlation Matrix between pairs of variables.

Author Contributions: L.M. and D.M. conceived and designed the study, implemented the statistical methodology and analyzed the data, authored and reviewed drafts of the paper, approved the final draft. F.B. analyzed the data, prepared figures and tables, authored and reviewed drafts of the paper, approved the final draft. S.M. contributed to the theoretical assumptions behind models, analyzed the data, authored and reviewed drafts of the paper, approved the final draft. All authors have read and agreed to the published version of the manuscript.

Funding: This research received no external funding

Acknowledgments: This paper uses data from release 6 of SHARE 2015. The SHARE data collection has been primarily funded by the European Commission through the 5th framework program (project QLK6-CT-2001-00360 in the thematic program Quality of Life). Additional funding came from the US National Institute on Aging (U01 AG09740-13S2, P01 AG005842, P01 AG08291, P30 AG12815, Y1-AG-4553-01 and OGHA 04-064). Data collection in Austria (through the Austrian Science Foundation, FWF), Belgium (through the Belgian Science Policy Office), and Switzerland (through BBW/OFES/UFES) was nationally funded. The SHARE data collection in Israel was funded by the US National Institute on Aging (R21 AG025169), by the German-Israeli Foundation for Scientific Research and Development (GIF), and by the National Insurance Institute of Israel. Further support by the European Commission through the 6th framework program (projects SHARE-I3, RII-CT-2006-062193, and COMPARE, CIT5-CT-2005-028857) is gratefully acknowledged. For methodological details, see Börsch-Supan, A. 
and H. Jürges (Eds.) (2005). The Survey of Health, Aging, and Retirement in Europe - Methodology. Mannheim: Mannheim Research Institute for the Economics of Aging (MEA)).

Conflicts of Interest: The authors declare no conflict of interest.

\section{References}

1. World Population Ageing 2017. Available online: https://www.un.org/en/development/desa/population/ theme/ageing/WPA2017.asp (accessed on 17 January 2020).

2. Joyce, G.F.; Keeler, E.B.; Shang, B.; Goldman, D.P. The lifetime burden of chronic disease among the elderly. Health Aff. 2005, 24 (Suppl. 2), W5R18-29. [CrossRef] [PubMed]

3. Baltes, P.B.; Baltes, M.M. Psychological perspectives on successful aging: The model of selective optimization with compensation. Success. Aging Perspect. Behav. Sci. 1990, 1, 1-34. [CrossRef]

4. Börsch-Supan, A.; Brandt, B.; Hunkler, C.; SHARE Central Coordination Team. Data resource profile: The Survey of Health, Ageing and Retirement in Europe (SHARE). Int. J. Epidemiol. 2013, 42, 992-1001. [CrossRef] [PubMed]

5. Börsch-Supan, A. Survey of Health, Ageing and Retirement in Europe (SHARE) Wave 6; Release Version: 6.1.0; Data set; SHARE-ERIC, MEA: Mannheim, Germany, 2018. [CrossRef]

6. Yamada, C.; Kengo, M.; Eiko, T. Self-rated health as a comprehensive indicator of lifestyle-related health status. Environ. Health Prev. Med. 2012, 17, 457-462. [CrossRef]

7. Wu, S.; Wang, R.; Zhao, Y.; Ma, X.; Wu, M.; Yan, X.; He, J. The relationship between self-rated health and objective health status: A population-based study. BMC Public Health 2013, 13, 320. [CrossRef]

8. Szeles, M.R. Comparative Examination of Self-Perceived Health and Other Measures of the Quality of Life across the EU-27. Soc. Indic. Res. 2018, 137, 391-411. [CrossRef]

9. Cohrdes, C.; Mensink, G.B.M.; Hölling, H. How you live is how you feel? Positive associations between different lifestyle factors, cognitive functioning, and health-related quality of life across adulthood. Qual. Life Res. 2018, 27, 3281-3292. [CrossRef]

10. Jylha, M. What is self-rated health and why does it predict mortality? Towards a unified conceptual model. Soc. Sci. Med. 2009, 69, 307-316. [CrossRef]

11. Lindström, M. Marital status, social capital, material conditions and self-rated health: A population-based study. Health Policy 2009, 93, 172-179. [CrossRef]

12. Constitution of the World Health Organization, 48th ed.; Basic Documents of the World Health Organization: Geneva, Switzerland, 2014; Available online: https://apps.who.int/gb/bd/PDF/bd48/basic-documents-48thedition-en.pdf (accessed on 17 January 2020).

13. Badawi, G.G.; Garié, G.; Pagé, V.; Schmitz, N. Indicators of self-rated health in the Canadian population with diabetes. Diabet. Med. 2012, 29, 1021-1028. [CrossRef]

14. Feng, Q.; Zhu, H.; Zhen, Z.; Gu, D. Self-rated health, interviewer-rated health, and their predictive powers on mortality in old age. J. Gerontol. B Psychol. Sci. Soc. Sci. 2016, 71, 538-550. [CrossRef] [PubMed]

15. Moor, I.; Spallek, J.; Richter, M. Explaining socioeconomic inequalities in self-rated health: A systematic review of the relative contribution of material, psychosocial and behavioural factors. J. Epidemiol. Community Health 2017, 71, 565-575. [CrossRef] [PubMed]

16. Karimi, M.; Brazier, J. Health, Health-Related Quality of Life, and Quality of Life: What is the Difference? Pharmacoeconomics 2016, 34, 645-649. [CrossRef] [PubMed]

17. Bowling, A. Measuring Health: A Review of Quality of Life Measurement Scales, 3rd ed.; Maidenhead, G.B., Ed.; Open University: Milton Keynes, England, 1997.

18. Rejeski, W.J.; Mihalko, S.L. Physical activity and quality of life in older adults. J. Gerontol. A Biol. Sci. Med. Sci. 2001, 56, 23-35. [CrossRef] [PubMed]

19. Kuyken, W.; Orley, J.; Hudelson PSartorius, N. Quality of life assessment across cultures. Int. J. Ment. Health 1994, 23, 5-27. [CrossRef]

20. Cummins, R.A. Moving from the quality of life concept to a theory. J. Intellect. Disabil. Res. 2005, 49, 699-706. [CrossRef]

21. Felce, D.; Perry, J. Quality of life: Its definition and measurement. Res. Dev. Disabil. 1995, 16, 51-74. [CrossRef] 
22. Berger, N.; Van Oyen, H.; Cambois, E.; Fouweather, T.; Jagger, C.; Nusselder WRobine, J.M. Assessing the validity of the Global Activity Limitation Indicator in fourteen European countries. BMC Med. Res. Methodol. 2015, 15, 1. [CrossRef]

23. Haseen, F.; Adhikari, R.; Soonthorndhada, K. Self-assessed health among Thai elderly. BMC Geriatr. 2010, 10, 30. [CrossRef]

24. Andel, R.; Merril, S.; Kareholt, I. The role of midlife occupational complexity and leisure activity in late-life cognition. J. Gerontol. B Psychol. Sci. Soc. Sci. 2015, 70, 314-421. [CrossRef]

25. Hertzog, C.; Kramer, A.F.; Wilson, R.S.; Lindenberger, U. Enrichment Effects on Adult Cognitive Development: Can the Functional Capacity of Older Adults Be Preserved and Enhanced? Psychol. Sci. Public Interest. 2008, 9, 1-65. [CrossRef] [PubMed]

26. Vásquez-Amézquita, M. Factores predictores de la reserva cognitiva en un grupo de adultos mayores. Predictors of cognitive reserve in a group of elderly. Rev. Chil. Neuropsicol. 2016, 11, 5-11. [CrossRef]

27. Miceli, S.; Maniscalco, L.; Matranga, D. Social networks and social activities promote current and later cognitive functioning of elderly people: Evidence from the SHARE survey. Eur. J. Ageing 2019, 16, 145-154. [CrossRef]

28. von dem Knesebeck, O.; Hyde, M.; Higgs, P.; Kupfer, A.; Siegrist, J. Quality of life and well-being. In Health, Ageing and Retirement in Europe-First Results from the Survey of Health, Ageing and Retirement in Europe; Börsch-Supan, A., Brugiavini, A., Jürges, H., Mackenbach, J., Siegrist, J., Weber, G., Eds.; MEA: Mannheim, Germany, 2005; pp. 199-203.

29. Bourassa, K.J.; Memel, M.; Woolverton, C.; Sbarra, D.A. Social participation predicts cognitive functioning in aging adults over time: Comparisons with physical health, depression, and physical activity. Aging Ment. Health 2017, 21, 133-146. [CrossRef] [PubMed]

30. Alvarez-Galvez, J. Discovering complex interrelationships between socioeconomic status and health in Europe: A case study applying Bayesian networks. Soc. Sci. Res. 2016, 56, 133-143. [CrossRef] [PubMed]

31. Borrat-Besson, C.; Ryser, V.A.; Gonçalves, J. An evaluation of the CASP-12 scale used in the Survey of Ageing and Retirement in Europe (SHARE) to measure Quality of Life among people aged 50+. In FORS Working Paper; Series 4; FORS: Lausanne, Switzerland, 2015. [CrossRef]

32. Hyde, M.; Wiggins, R.; Higgs, P.; Blane, D.B. A measure of quality of life in early old age: The theory, development and properties of needs satisfaction model. Aging Ment. Health 2003, 7, 186-194. [CrossRef]

33. Perret, R. The left frontal lobe of man and the suppression of habitual responses in verbal categorical behaviour. Neuropsychologia 1974, 12, 323-330. [CrossRef]

34. Diesfeldt, H.F.A. Verbal fluency in senile dementia: An analysis of search and knowledge. Arch. Gerontol. Geriatr. 1985, 4, 231-239. [CrossRef]

35. Lewis, F.I. Bayesian networks as a tool for Epidemiological System Analysis. In Proceedings of the 9th International Conference on Mathematical Problems in Engineering, Aerospace and Sciences (ICNPAA 2012), Vienna, Austria, 10-14 July 2012; pp. 610-617.

36. Pittavino, M.; Dreyfus, A.; Heuer, C.; Benschop, J.; Wilson, P.; Collins-Emerson, J.; Torgerson, P.R.; Furrer, R. Comparison between generalized linear modelling and additive Bayesian network; identification of factors associated with the incidence of antibodies against Leptospira interrogans sv Pomona in meat workers in New Zealand. Acta Trop. 2017, 173, 191-199. [CrossRef]

37. Lewis, F.I.; Ward, M.P. Improving epidemiologic data analyses through multivariate regression modelling. Emerg. Themes Epidemiol. 2013, 17, 4. [CrossRef]

38. Kratzer, G.; Pittavino, M.; Lewis, F.I.; Furrer, R. abn: An R package for modelling multivariate data using additive Bayesian networks. R package version 1.1. 2017. Available online: https:/CRAN.R-project.org/ package $=$ abn (accessed on 17 January 2020).

39. Golinowska, S.; Groot, W.; Baji, P.; Pavlova, M. Health promotion targeting older people. BMC Health Serv. Res. 2016, 16 (Suppl. 5), 345. [CrossRef] [PubMed]

40. Eurostat Regional Yearbook 2018. Available online: https://ec.europa.eu/eurostat/web/products-statisticalbooks/-/KS-HA-18-001 (accessed on 17 January 2020).

41. Chen, P.; Ratcliff, G.; Belle, S.H.; Cauley, J.A.; DeKosky, S.T.; Ganguli, M. Cognitive tests that best discriminate between pre-symptomatic AD and those who remain non demented. Neurology 2000, 55, 1847-1853. [CrossRef] [PubMed] 
42. Van Oyen, H.; Bogaert, P.; Yokota, R.T.C.; Berger, N. Measuring disability: A systematic review of the validity and reliability of the Global Activity Limitations Indicator (GALI). Arch Public Health 2018, 76, 25. [CrossRef] [PubMed]

43. Arnadottir, S.A.; Gunnarsdottir, E.D.; Stenlund, H.; Lundin-Olsson, L. Determinants of self-perceived health in old age: A population-based, cross-sectional study using the International Classification of Functioning. BMC Public Health 2011, 11, 670. [CrossRef]

44. Pinillos-Franco, S.; Somarriba, N. Examining gender health inequalities in Europe using a Synthetic Health Indicator: The role of family policies. Eur. J. Public Health 2019, 29, 254-259. [CrossRef]

45. Croezen, S.; Burdorf, A.; van Lenthe, F.J. Self-perceived health in older Europeans: Does the choice of survey matter? Eur. J. Public Health 2016, 26, 686-692. [CrossRef]

46. McKinlay, J.; Marceau, L. US public health and the 21st century: Diabetes mellitus. Lancet 2000, 356, 757-761. [CrossRef]

47. Fornell, B.; Correa, M.; López del Amo, M.P.; Martín, J.J. Influence of changes in the Spanish labor market during the economic crisis (2007-2011) on perceived health. Qual. Life Res. 2018, 27, 2095-2105. [CrossRef]

48. Tsimbos, C. An assessment of socio-economic inequalities in health among elderly in Greece, Italy and Spain. Int. J. Public Health 2010, 55, 5-15. [CrossRef]

49. Matranga, D.; Tabacchi, G.; Cangialosi, D. Sedentariness and weight status related to SES and family characteristics in Italian adults: Exploring geographic variability through multilevel models. Scand. J. Public Health 2018, 46, 548-556. [CrossRef]

50. Bono, F.; Matranga, D. Socioeconomic inequality in non-communicable diseases in Europe between 2004 and 2015: Evidence from the SHARE survey. Eur J Public Health 2019, 29, 105-110. [CrossRef] [PubMed]

51. Smith, K.W.; Avis, N.E.; Assmann, S.F. Distinguishing between quality of life and health status in quality of life research: A meta-analysis. Qual. Life Res. 1999, 8, 447-459. [CrossRef] [PubMed]

52. Sposito, G.; D’Elboux Diogo, M.J.; Cintra, F.A.; Neri, A.L.; Guariento MEDe Sousa, M.L.R. Relationship between subjective well-being and the functionality of elderly outpatients. Rev. Bras Fisioter. 2010, 14, 81-89. [CrossRef] [PubMed]

53. Gilmour, H. Social participation and the health and well-being of Canadian seniors. Health Rep. 2012, 23, 23-33. [PubMed]

54. Bombak, A.E. Self-rated health and public health: A critical perspective. Front. Public Health 2013, 1, 15. [CrossRef]

55. Somrongthong, R.; Hongthong, D.; Wongchalee, S.; Wongtongkam, N. The influence of chronic illness and lifestyle behaviors on quality of life among older Thais. BioMed. Res. Int. 2016, 2016, 2525941. [CrossRef]

56. Haugrud, N.; Crossley, M.; Vrbancic, M. Clustering and switching strategies during verbal fluency performance differentiate Alzheimer's disease and healthy aging. J. Int. Neuropsychol. Soc. 2011, 17, 1153-1157. [CrossRef]

57. Health 2020: A European Policy Framework Supporting Action across Government and Society for Health and Well-being. Available online: http://www.euro.who.int/en/health-topics/health-policy/health2020-the-european-policy-for-health-and-well-being/publications/2013/health-2020.-a-european-policyframework-and-strategy-for-the-21st-century-2013the14thJan2020 (accessed on 17 January 2020).

(C) 2020 by the authors. Licensee MDPI, Basel, Switzerland. This article is an open access article distributed under the terms and conditions of the Creative Commons Attribution (CC BY) license (http://creativecommons.org/licenses/by/4.0/). 